\title{
Global BEEHIVE: developing good practice for multilateral, scalable, and sustainable virtual exchange
}

\author{
Allen Guidry ${ }^{1}$, Jami Leibowitz ${ }^{2}$, and Tope Adeyemi-Bello ${ }^{3}$
}

Abstract

$\tau$ n preparing students for life beyond the university, higher education must develop graduates who are culturally competent and understanding of the world beyond their own region. An appropriate context to address this area of need is Virtual Exchange (VE). Following the Global Partners in Education $\left(\mathrm{GPE}^{4}\right)$ model, this practice report presents the process used by a collaborative international project design team to develop two 'Global Understandings' (GU) courses; one in business and one in education. It further presents an extension of an established general education multilateral (more than two international partners) VE GU course by using it as a model to develop topic specific VE courses in high interest and high capacity areas within the partner institutions. After undertaking the initial steps for developing topic specific VE courses in business and education, program designers found that planning workshops, team leadership, clear organizational documents and processes, clear communication policies, logistical support, and faculty enthusiasm and buy-in were key factors in effective course design and implementation in the initial project stages. In addition to sharing the project design process, this practice report also presents the lessons learned along with considerations for future implementation.

Keywords: virtual exchange; telecollaboration; global education; intercultural competence; global partnerships.

1. East Carolina University; guidrya@ecu.edu; https://orcid.org/0000-0001-8933-3343

2. East Carolina University; leibowitzj@ecu.edu; https://orcid.org/0000-0001-5951-6325

3. East Carolina University; bellot@ecu.edu; https://orcid.org/0000-0002-4174-1388

4. East Carolina University Global Academic Initiatives: https://thegpe.org/

How to cite this article: Guidry, A., Leibowitz, J., \& Adeyemi-Bello, T. (2020). Global BEEHIVE: developing good practice for multilateral, scalable, and sustainable virtual exchange. Journal of Virtual Exchange, 3 (SI-IVEC2019), 13-26. https://doi.org/10.21827/jve.3.35808 


\section{Introduction}

In the current geo-political environment where student mobility is limited, it is important to prepare undergraduate students with the skills necessary to interact and engage with international partners in the global marketplace. In preparing students for life beyond the university, higher education must equip graduates who are culturally competent and have a global perspective, especially if their lived experience has not allowed them to travel out of their local region. An appropriate place to address this area of need is in international VE courses. VE supplements more traditional means of international studies by using innovative, technology-based learning strategies to provide students with direct intercultural experiences. In VE, students work collaboratively with peers around the world on common coursework or projects in facilitated settings that promote intercultural skillbuilding (The EVALUATE Group, 2019). Through this modality, in addition to gaining their contentbased knowledge, students also build intercultural communication and collaboration skills, cultural competence, and awareness. By directly linking students from different nations and cultures through a shared educational experience, university instructors can begin to tear down the walls of stereotypes and misinformation and begin to build bridges of understanding and shared humanity.

\section{Context}

East Carolina University, a regional university in a predominantly rural area in the southeastern United States of America (from here forward called 'host institution'), first offered a VE course in the summer of 2003. Over the years, this experiment has grown to 30-40 full semester, multilateral (more than two international partners) VE courses per year. The partnerships developed through these multilateral VE agreements led to the development of a consortium of institutions in 2008 called GPE. The GPE now includes 49 institutions of higher education in 25 countries, all of which regularly participate in GPE's signature program, the GU course ${ }^{5}$. Students at GPE institutions engage in bi-weekly synchronous discussions with up to three global partners each semester. At the host institution, these courses are primarily offered as general education courses and also fulfill a global diversity requirement. The courses are offered in ten academic areas ranging from anthropology and sociology to communication and political science and focus on the development of intercultural skills through student-led discussions and collaborative projects.

The GU course takes a centrally managed model approach to VE. All participating partners agree to follow the policies, practices, and procedures outlined in a foundational document referred to

5. https://thegpe.org/ 
as the GU core. The GU core also defines broad topics and a framework for collaborative projects. All GU courses follow the same GU core regardless of their disciplinary base. This award-winning approach has proven to be sustainable and scalable and has produced very positive student learning outcomes (Eppler \& Wynn, 2019).

\section{Objectives}

This practice report shares an extension of the established GU course by using it as a model to develop topic specific VE courses in targeted high interest and high capacity areas within the partner institutions. Funded by the U.S. Department of Education Undergraduate International Studies and Foreign Language Program Grant ${ }^{6}$, the Global Business, Education, Environment, and Health International VE (Global BEEHIVE) project was created to design and deliver courses in four content areas: Global Business (GB), Global Education (GE), global environment, and global health. This grant was developed through a collaboration between the host institution and three partner institutions, per course. These areas were chosen because they represented great capacity for student enrollment, but were at present under-enrolled in GU courses. Of the 437 students at the host institution who enrolled in a GU course in 2017/2018, there were only 15 business students, 36 education students, 42 students in a health-related field, and 36 students studying the natural sciences. These numbers do not proportionally align with the number of students majoring in each area. The Global BEEHIVE was conceived as a way to engage students and faculty in these areas. The purpose of this study is to share the process used in developing the business and education Global BEEHIVE courses and to illuminate some of the opportunities and challenges faced in both designing and delivering the courses.

\section{Literature review}

Among global education practitioners, VE in its many forms, has been celebrated as a way to allow an ever-larger population of students the opportunity to gain "meaningful intercultural experience" across a wide array of academic disciplines (Jager et al., 2019, p. 7). In many institutions of higher education, these VEs have been introduced to help meet the challenge of "preparing students to be world citizens who possess holistic perspectives on diversity and inclusion” (Zhang \& Pearlman, 2018, p. 2). Projects and models like the State University of New York Collaborative Online International

6. https://www2.ed.gov/programs/iegpsugisf/index.html 
Learning (SUNY, COIL ${ }^{7}$ ) model and the GPE ${ }^{8}$ model have created processes for engaging faculty and students from around the world in these 'meaningful intercultural experiences' that, ideally, produce informed global citizens.

These programs have been deemed quite effective in producing 'globally minded' students, as evidenced by a number of studies. Wang et al. (2017) found that students were satisfied with an international collaborative course in intralogistics education and that those students found the experience to be a positive one. These findings were similar to those of Akbaba and Baskan (2017) who found that students involved in an international blended learning project (including VE) felt that the experience was rewarding and enhanced their overall learning experience. Perhaps these positive experiences derive from the benefits of VE, such as learning through multiple cultural lenses, developing diverse personal relationships, and negotiating meaning with virtual teams (Fowler, Pearlman, LeSavoy, \& Hemphill, 2014). Shrivastava (2018) found in a study of international virtual teams that the experience was "eye opening” and that VEs were "a good source of not only knowledge creation but also output orientation” (p. 13). Adkins (2013) certainly has echoed these findings that international virtual teams can be effective in developing teamwork and communication skills. Similarly, Korsager and Slotta (2015) found that students participating in an international virtual collaboration were able to explain the perspectives of international partners over time and were also more adept at organizing and connecting relevant concepts. The benefits of VE are diverse and well documented.

Yet, there are some lessons to be learned regarding VE. Wang et al. (2017) warn that language skills of partners, different time zones, and lack of prior knowledge can all be stressors for students engaged in VE. They also suggest that utilizing an expanded number of partners and focusing on real-world cases are beneficial. Adkins (2013) noted that frequent informal check-ins are good practice, as well as monitoring student communication with an instructor ready to intervene in the event there is a lapse in communication between international partners. This monitoring and intervention role is also noted by Korsager and Slotta (2015). Finally, Akbaba and Baskan (2017) contend that utilizing a mix of traditional and digital learning methodologies is most effective and provides a "personalized learning experience” (p. 13).

Despite the great promise of VE, Jager et al. (2019) argue that there are a number of problems related to VE in higher education including:

7. http://coil.suny.edu/

8. https://thegpe.org/ 
- the current level of awareness of VE is not very high;

- VE is not a common practice in higher education;

- educators implementing VE do not receive a great deal of support; and

- there is a lack of integrated approaches to VE that build on common understandings, visions, or implementation supports (p. 23).

The current literature suggests that although there are many different forms of VE, from seminars to teams to projects, there are limited holistic models of how to engage in VE (Jager et al., 2019). Furthermore, the literature suggests that most of the international connections take the form of bi-lateral exchanges between two universities. Very few exchanges presented in the literature comprise multilateral VEs where variances in cultural contexts between partners might be fully explored. This practice report seeks to fill that void by presenting the process used in designing a project that includes multilateral, synchronous VE through the use of an established 'core' or model with an integrated support network.

\section{Project design - the Global BEEHIVE}

\subsection{General structure and activities}

The goal of the Global BEEHIVE project was to advance comprehensive internationalization at the host institution by expanding existing VE programming to introduce international perspectives into the fields of business, education, healthcare, and environmental science. The objectives were to:

- expand access to international studies courses, and the GU Certificate, for students with traditionally limited exposure during their academic careers;

- increase interest in international studies, foreign language, and study abroad among students in business, education, environmental science, and health disciplines; and

- improve intercultural communication and collaboration skills, cultural competence, and cultural intelligence among participating students.

The Global BEEHIVE framework, like the GU model for VE, consists of three equally important components: (1) the core policies, practices, and procedures mutually agreed to by all participants; (2) the shared components of the course, including content and common assignments; and (3) the independent, local components of the course. The core policies, practices, and procedures followed the GU model with modifications to account for any specific needs for the individual courses. 


\section{Figure 1. Overall Global BEEHIVE curriculum design process with detail of curriculum design workshop}

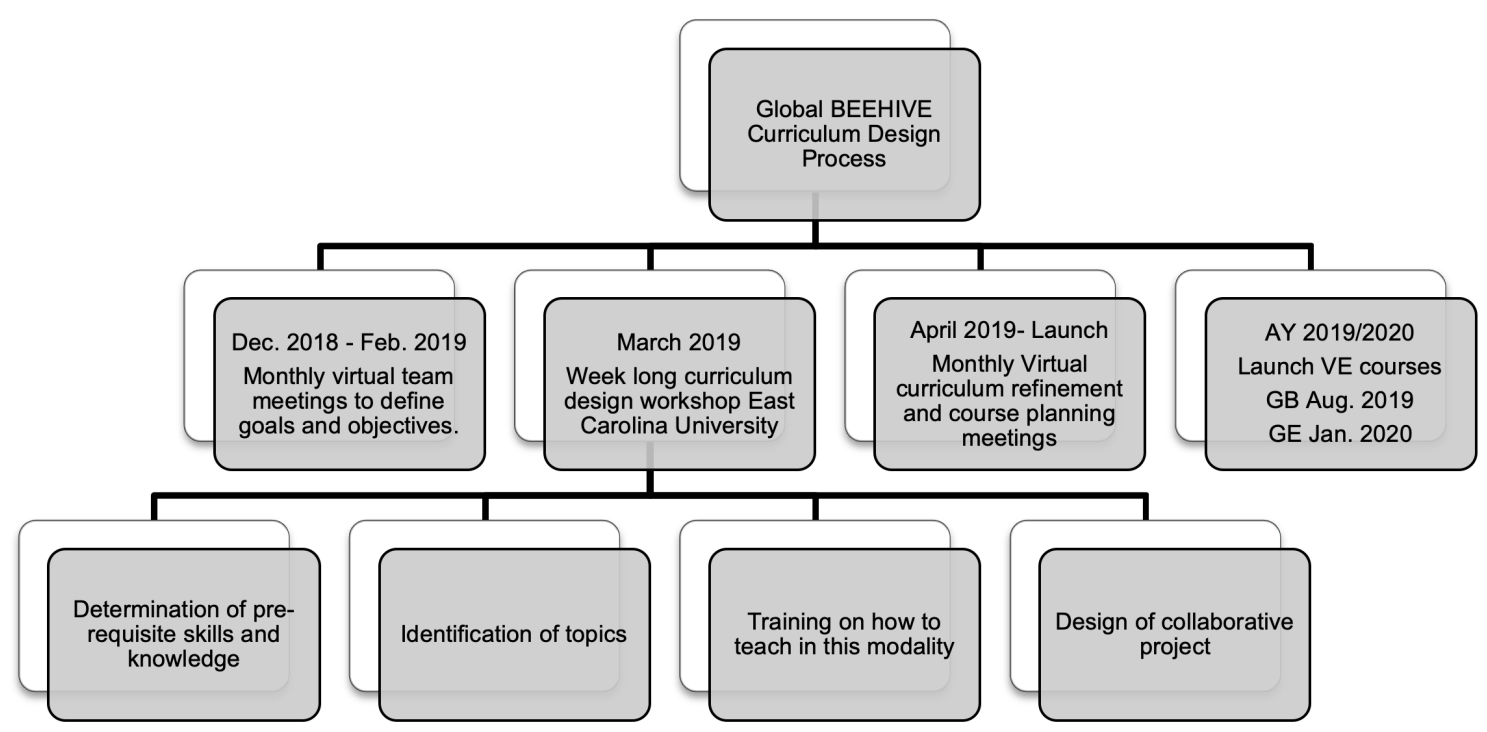

Figure 1 illustrates the overall curriculum design process used by the Global BEEHIVE participants with specific detail demonstrating the process used in the week-long curriculum design workshop for creating the GB and GE courses. As stated previously, GB and GE were chosen because they represented academic areas of great capacity for student enrollment but were at present underenrolled in GU courses. The collaborative components for each course were built by independent design teams consisting of at least one faculty member from the host institution, East Carolina University, and corresponding faculty from three international partner institutions. Through online workshops and discussions, the faculty learned about best practices for teaching in a VE environment and all partners worked with host institution project leadership to develop the core document for each course that would articulate the collaborative portion of the course. Global BEEHIVE Project leaders at East Carolina University facilitated the week-long workshop, emphasizing the importance of developing a core that was sustainable and scalable and would allow for additional partners to join the course in the future, while at the same time providing space for the course designers to negotiate content topics that would be relevant for their specific audiences. Table 1 illustrates the general design schedule for both courses, including the timeline for connections (specified period of time interacting with international partners) and the number of VE joint sessions. 
Table 1. Semester schedule for an individual partner participating in multilateral virtual exchange

\begin{tabular}{|c|c|c|c|c|c|c|}
\hline \multirow{7}{*}{$\begin{array}{l}\text { Local } \\
\text { Preparation }\end{array}$} & $\begin{array}{l}\text { 3-4 Weeks - } \\
\text { Partner A }\end{array}$ & \multirow{7}{*}{$\begin{array}{l}\text { Local Synthesis } \\
\text { \& Preparation }\end{array}$} & $\begin{array}{l}\text { 3-4 Weeks - } \\
\text { Partner B }\end{array}$ & \multirow{7}{*}{$\begin{array}{l}\text { Local Synthesis } \\
\text { \& Preparation }\end{array}$} & $\begin{array}{l}\text { 3-4 Weeks - } \\
\text { Partner C }\end{array}$ & \multirow{7}{*}{$\begin{array}{l}\text { Local Synthesis } \\
\text { \& Assessment }\end{array}$} \\
\hline & Link 1: Intros & & Link 1: Intros & & Link 1: Intros & \\
\hline & Link 2: Topic 1 & & Link 2: Topic 1 & & Link 2: Topic 1 & \\
\hline & Link 3: Topic 2 & & Link 3: Topic 2 & & Link 3: Topic 2 & \\
\hline & Link 4: Topic 3 & & Link 4: Topic 3 & & Link 4: Topic 3 & \\
\hline & Link 5: Topic 4 & & Link 5: Topic 4 & & Link 5: Topic 4 & \\
\hline & $\begin{array}{l}\text { Link 6: } \\
\text { Collaborative } \\
\text { Projects }\end{array}$ & & $\begin{array}{l}\text { Link 6: } \\
\text { Collaborative } \\
\text { Projects }\end{array}$ & & $\begin{array}{l}\text { Link 6: } \\
\text { Collaborative } \\
\text { Projects }\end{array}$ & \\
\hline
\end{tabular}

Although the GB and GE courses had unique topics and projects, their overall models were similar. Over the semester, each participating partner class (total of four) would hold synchronous online meetings with another partner class individually twice a week for three to four weeks. These synchronous meetings were called 'links' and when meeting they were said to be 'linking' (see Table 1). Once the links with the first partner had concluded, they would move on to repeat the process with a second and then third partner. During the three- to four-week module, the students discussed a set progression of topics as agreed upon by the design team and outlined in the core. Students would also complete collaborative projects with an assigned partner student from each partner university. These projects varied in topic and design, like the courses themselves, but had a common framework in which students were required to work with their assigned partner on the project outside of class time to analyze a situation and produce a negotiated product or response.

\subsection{GB course}

The GB course was designed to enhance the cultural savviness of participating students with regard to select macro topics of interest to the partner institutions. The agreed-upon objectives of the collaboration were to:

- develop intercultural communication and collaboration skills relevant to business;

- demonstrate increased cultural intelligence and competence;

- assess cultural differences in business practices in international contexts; and

- build problem-solving and strategic decision making abilities through case analysis.

During the development phase of the GB course, the design team consisting of business faculty from China, France, Mexico, and the US, reached consensus about finding a case that would provide an 
applications-oriented forum for the course topics. Given the diversity of topics, negotiation was required for selecting a satisfactory business case for collaborating partners.

The team agreed that each partner should champion the content for the subject matter that is of strategic importance to their institution and/or college. Table 2 presents the discussion topic progression for each link in the GB course.

\section{Table 2. Discussion topic progression for GB course}

\begin{tabular}{|l|l|l|}
\hline Link & Topic & Activity \\
\hline 1 & Introductions & Each student is required to prepare a short, but memorable, introduction. \\
\hline 2 & Business protocols and etiquette & Students research partner country's business protocols and etiquette. \\
\hline 4 & Business environment and systems & Students research partner country's business environment and system. \\
\hline $\begin{array}{l}\text { Case study part 1 - Doing } \\
\text { business in a foreign country } \\
\text { when you are a multinational }\end{array}$ & $\begin{array}{l}\text { Partner instructors collaborate to select a topic (leadership, } \\
\text { competition, market segmentation, or entry mode) for general } \\
\text { discussion. Students research the partner country based on } \\
\text { the topic selected by the collaborating instructors. }\end{array}$ \\
\hline 5 & $\begin{array}{l}\text { Case study part 2-Doing } \\
\text { business in a foreign country } \\
\text { when you are a multinational }\end{array}$ & $\begin{array}{l}\text { Students apply the content from the previous link to a case selected } \\
\text { by the design team, identify problems raised by the case study, and } \\
\text { brainstorm solutions to the problems identified in the case. }\end{array}$ \\
\hline 6 & $\begin{array}{l}\text { Collaborative project } \\
\text { Students work with their assigned peer at their partner university } \\
\text { to develop a presentation that represents a negotiated analysis and } \\
\text { recommendation about the topic selected and discussed in the prior two } \\
\text { links (leadership competition, market segmentation, or entry mode). }\end{array}$ \\
\hline
\end{tabular}

\subsection{GE course}

The GE course was designed as a comparative education course that explored common topics of interest to those interested in and/or actively pursuing K-12 educational studies. The prevailing approach of the course designers from the outset was that the multilateral VE environment would provide students with an opportunity to not only view educational theory and practice through a window into other international educational systems, but also to serve a reflective purpose as they looked into the mirror of their own educational system.

The design team, consisting of education faculty from Chile, China, the Netherlands, and the US, agreed upon the following course-specific objectives (in addition to stated core objectives):

- students will identify and reflect on their own value structure related to educational systems and practice; 
- students will articulate their own value structure with individuals and groups from a variety of international cultures;

- students will compare and contrast their own value structures related to educational systems and practice with those in other international cultures; and

- students will build intercultural competence by understanding their own value structure and how it influences successful engagement with others.

The GE course designers then agreed upon a rudimentary set of pre-requisite skills and knowledge for students entering the course. These included:

- students need to possess an intermediate level of verbal and written English language skills;

- students will know and understand general components of their local educational context; and

- students possess basic knowledge about the countries of the partner institutions (e.g. simple statistical information related to geography, history, political structure, population density).

Finally, the GE team compiled and negotiated a list of discussion topics for each of the links. Beginning with 18 initial topics, the team was able to come to consensus on five universally applicable topics that would be presented through a series of core questions. Table 3 presents the discussion topic progression for each link in the GE course.

\section{Table 3. Discussion topic progression for GE course}

\begin{tabular}{|l|l|l|}
\hline Link & Topic & Core Question \\
\hline 1 & Introductions & $\begin{array}{l}\text { How did your partners represent your education system? } \\
\text { What would you add to help their understanding? }\end{array}$ \\
\hline 2 & School funding & What is the appropriate role of the public/government in funding schools? \\
\hline 3 & Educational equity & $\begin{array}{l}\text { What are your thoughts on the power of } \\
\text { education to transform peoples' lives? }\end{array}$ \\
\hline 4 & Evaluation systems in education & $\begin{array}{l}\text { How might we use assessment/evaluation to } \\
\text { make students more 'future ready'? }\end{array}$ \\
\hline 5 & $\begin{array}{l}\text { Moderating behavior and } \\
\text { classroom management }\end{array}$ & $\begin{array}{l}\text { In what ways does classroom management contribute to the development } \\
\text { of the 'whole child' (cognitively, affectively, socially, etc.)? }\end{array}$ \\
\hline 6 & $\begin{array}{l}\text { Collaborative project } \\
\text { Students work with partners from partner universities to determine an } \\
\text { educational topic of common interest. Student teams research their topic, } \\
\text { identify a common problem related to that topic, and collaboratively propose } \\
\text { a solution to the problem. Solution is presented to the combined classes. }\end{array}$ \\
\hline
\end{tabular}




\section{Discussion of outcomes}

\subsection{Overall}

One of the key pieces to designing the content specific GB and GE courses was to allow space for course designers to familiarize themselves with their global partners' contexts. This, in itself, was an exercise in developing cultural understanding for the course designers and an authentic example of the benefit of the approach to those soon-to-be BEEHIVE instructors. The grant-funded week-long institute was also important in helping course designers develop effective communication protocols. Without the luxury of this funding, the very meaningful, collaborative experience would likely not have been possible, yet this was a key to planning and instruction in a VE environment and allowed designers to work out logistical details. The design process also afforded designers the opportunity to learn about each other's priorities and opened opportunities to discuss and come to agreement on 'must haves' in the course. Each partner was provided a voice in the dialogue and this collaborative negotiating process created a positive climate and shared sense of purpose. We recognize that this process was made possible through the support of a grant. Without the grant we likely would not have been able to have the week-long workshops which, we feel, greatly enhanced the ability of the partner institutions to create and deliver these courses.

\subsection{Lessons learned - GB}

Upon reflection, faculty in the GB team (the team to first offer their GUs course under this model) indicated a number of observations and lessons learned. Regarding preparation, GB faculty found that a VE course required the instructors to incorporate significant forethought into the design and administration of their courses. An agenda for each class meeting has to be developed a week or more before each joint session and resources shared with students in advance. Further, while the collaborating instructors have to be in communication with each other at least one semester before the actual links to design and set up the sequencing of course content, per the GU core requirement, they have to be in more constant communication with each other about two weeks before the first link and throughout the linking period. Next, GB faculty reported that the VE course required the instructor to help facilitate rapport among his/her own students before the first session (and of course throughout the semester). If local students were not comfortable with each other, the potential for the VE sessions to be awkward is higher.

From an instructional perspective, the VE format used by GB was, in a sense, a form of team teaching. This provided the instructors the opportunity to develop cross-cultural relationships with his/her colleagues (and sometimes learn along with the students). GB faculty also indicated that the 
preparation of the instructors in a VE course during the joint sessions was more student-focused (i.e. designed to help the students adequately prepare for the class meeting). The instructor needs the skills to guide the discussion during the joint sessions. S/he also needs to know when to intervene in a discussion and when to let it go. Therefore, it is imperative that the instructor be flexible and adaptable. GB faculty felt that the attitude of the instructor in the VE course will, at a minimum, be reflected by the attitude of the students. In essence, the instructor needs to be a positive influence in the classroom. Finally, as with any VE, technology does not always work perfectly. It is the instructor's responsibility to help students deal in a positive way with some of the imperfections of the technological component of the course.

GB faculty indicated that perhaps the biggest regret in the process of developing the course was not keeping a journal to document it. While faculty had extensive notes about course content, there was very little reflection about interacting among colleagues with regard to the fun, challenges, and celebrations that accompanied the collaboration.

\subsection{Lessons learned - GE}

From the outset, the greatest hurdle that the GE course design team had to overcome was the concept of the model - that this course (1) had to be designed in a way that would apply and resonate equally in other institutions as well as their own institution, and (2) that it was about the broader subjects under exploration from a global perspective rather than the instructor's own predisposed manner of presenting the topics from within their own individualized context. Each of the instructors brought with them deep content expertise derived from their varied educational contexts, but often that expertise and those contexts were limiting when applied to other content areas and educational contexts. When working through the course design process it became imperative to reiterate the notion of the model that would suit not only the situations of those present, but also those of future partners. When planning for the collaborative sessions this forced course designers to think outside of their own expertise, to give up their own content agendas, and look to the needs of students across global educational contexts. It was necessary to continually reconvey that certain topics could be explored in 'local time' (i.e. time when faculty would meet with their own students independently) and that for the sake of the model, some topics that were relevant only to one educational context might need to be tabled in favor of more universal topics.

Since many of these conversations about topics and contexts were so deep and since time was limited for course development, it became necessary for a team leader to emerge who could move the conversation along when debates and deliberations extended over a long period of time. This team leader also served to remind the group of the importance of the 'model' and helped ensure that 
all voices were heard during the deliberative process. This latter point was particularly important for those team members with limited English proficiency. The team leader also served to generate organizational documents intended to refocus course designers on tasks and to provide a framework for creating outputs such as artifacts and worksheets.

As decisions were made and content was being developed, it became important to have an organizing document that allowed team members to work over time and across distance. Aside from serving as a focal point of discussion and providing a tangible product to work toward, the organizing document allowed team members to continue their work and course decision making beyond the course design workshop. For the GE team this document took the form of a cloud-based document sharing system that was accessible to all course design team members in their home countries. Additionally, an academic social networking site was used to help course designers stay in contact, share ideas, and disseminate documents. These collaborative spaces and tools were critical to allowing team members to sustain their work together.

One difficulty the GE group shared was finding accessible text resources that might be shared for the joint session discussions. Whereas texts were readily available in the home language of each institution, texts that were intended for the joint learning sessions needed to be in English, at appropriate reading levels, and accessible for current and future partners. Many of the texts that met these three criteria were generic in nature and shared only rudimentary information about the educational contexts in each country. This is an area that the course design team continues to work on and that will likely be an ongoing part of the early iterations of the GE course.

\section{Conclusions}

VE is regarded as a positive and rewarding learning tool in higher education (Akbaba \& Baskan, 2017; Wang et al., 2017) and is a valuable tool for developing teamwork and thinking skills (Adkins, 2013; Korsager \& Slotta, 2015), as well as developing intercultural knowledge and interpersonal skills (Fowler et al., 2014). Yet, many higher education institutions are unable (for financial or infrastructure reasons) or choose not to (for infrastructure or logistical reasons) employ this effective practice (Jager et al., 2019). The Global BEEHIVE project, through use of multilateral VE, employs a structured core that defines broad topics and a framework for collaborative projects. This approach allows practitioners to focus on quality of implementation and communication with international partners. The project also extends the content of GU courses to specific disciplines that allow international exchange to expand and grow in targeted high interest and high capacity areas across potential, future host campuses. 
The Global BEEHIVE provides insights regarding good practice in designing multilateral VE learning experience for students in higher education. The design process provides a number of key lessons for those desiring to implement similar projects in other VE contexts:

- a design workshop is key to communicating both the nature and need for a model approach and for developing communication protocols for design and implementation teams;

- leadership and clear organizational protocols are needed to maximize time in the workshop and in follow-up design activities;

- planning and communication protocols must be carefully put in place well in advance of the first joint session with each partner;

- a strong logistical infrastructure is essential to assuring quality of instructional time in implementation; and

- excitement, enthusiasm, and a belief in intercultural learning are essential to both effective design and implementation of a multilateral VE course.

With the promise of positive benefits stemming from this educational experience, it is logical that an analysis of the effectiveness of this approach must follow. If the value of such VE experiences can be communicated by those implementing innovative practices in the field, then perhaps institutions of higher learning will begin to embrace the practice and invest resources to develop meaningful learning experiences that better prepare students for global citizenship.

\section{References}

Adkins, J. K. (2013). Virtual teams and synchronous presentations: an online class experience. Information Systems Education Journal, 11(4), 61-65.

Akbaba, Y., \& Baskan, F. (2017). How to merge courses via Skype? Lessons from an international blended learning project. Research and Learning Technology, 25. https://doi.org/10.25304/rlt.v25.1915

Eppler, M. A., \& Wynn, T. (2019, May). Global understanding survey results: annual assessment report for Spring 2018 and Fall 2018. Unpublished manuscript.

Fowler, J. E., Pearlman, A. M. G., LeSavoy, B., \& Hemphill, D. (2014). Opening SUNY to the world: implementing multi-cultural curricular internationalization through the COIL network case studies from SUNY Oswego and College of Brockport. Cornell University, Ithaca, NY, May 27-30, 2014. The $23^{\text {rd }}$ SUNY Conference in Instruction and Technology.

Jager, S., Nissen, E., Helm, F., Baroni, A., \& Rousset, I. (2019). Virtual exchange as innovative practice across Europe: awareness and use in higher education: EVOLVE project baseline study. https://evolve-erasmus.eu/wp-content/ uploads/2019/03/Baseline-study-report-Final_Published_Incl_Survey.pdf 
Korsager, M., \& Slotta, J. (2015). International peer collaboration to learn about global climate changes. International Journal of Environmental and Science Education, 10(5), 717-736.

Shrivastava, A. (2018). Using connectivism theory and technology for knowledge creation in cross-cultural communication. Research in Learning Technology, 26. https://journal.alt.ac.uk/index.php/rlt/article/view/2061

The EVALUATE Group. (2019). Evaluating the impact of virtual exchange on initial teacher education: a European policy experiment. Research-publishing.net. https://doi.org/10.14705/rpnet.2019.29.9782490057337

Wang, R., Rechl, F., Bigontina, S., Fang, D., Gunthner, W. A., \& Fottner, J. (2017). Enhancing intercultural competence of engineering students via GVT (Global Virtual Teams) - based virtual exchanges: an international collaborative course in intralogistics education. Paper presented at the International Association for Development of the Information Society (IADIS) International Conference on E-Learning (Lisbon, Portugal, Jul 20-22, 2017). https://files. eric.ed.gov/fulltext/ED579381.pdf

Zhang, J., \& Pearlman, A. M. G. (2018). Expanding access to international education through technology enhanced collaborative online international learning (COIL) courses. International Journal of Technology in Teaching and Learning, 14(1), 1-11. 


\section{Virtual Exchange?}

Published by University of Groningen Press | UGP, a not-for-profit press

Groningen, The Netherlands | UGP@rug.nl

(C) 2020 UNICollaboration (collective work)

(C) 2020 by Authors (individual work)

Journal of Virtual Exchange 2020

Edited by Carolin Fuchs and Müge Satar

Special issue edited by Penelope Margaret Orton, Natesha L Smith-Isabell, and Mary Jane Radford Arrow

Publication date: 2020/11/20

Journal of Virtual Exchange (JVE) is an online, open-access, peer-reviewed journal aimed at practitioners and researchers in the field known variously as virtual exchange, telecollaboration, or online intercultural exchange. It is the official journal of UNICollaboration (https://www.UNICollaboration.org/), the international academic organisation dedicated to supporting and promoting telecollaboration and virtual exchange in higher-level education.

Rights. The whole volume is published under the Attribution-NonCommercial-NoDerivatives 4.0 International licence (CC BY-NCND 4.0); individual articles may have a different licence. Under the CC BY-NC-ND licence, the volume is freely available online for anybody to read, download, copy, and redistribute provided that the author(s), editorial team, and publisher are properly cited. Commercial use and derivative works are, however, not permitted.

Disclaimer. University of Groningen Press does not take any responsibility for the content of the pages written by the authors of this article. The authors have recognised that the work described was not published before, or that it was not under consideration for publication elsewhere. While the information in this article is believed to be true and accurate on the date of its going to press, neither UniCollaboration nor University of Groningen Press can accept any legal responsibility for any errors or omissions. Additionally, the publisher makes no warranty, expressed or implied, with respect to the material contained herein. While University of Groningen Press is committed to publishing works of integrity, the words are the authors' alone.

Trademark notice. Product or corporate names may be trademarks or registered trademarks, and are used only for identification and explanation without intent to infringe.

Copyrighted material. Every effort has been made by the editorial team to trace copyright holders and to obtain their permission for the use of copyrighted material in this article. In the event of errors or omissions, please notify the publisher of any corrections that will need to by incorporated in future editions of this article.

Typeset by Research-publishing.net (https://research-publishing.net)

Noto fonts are open source. All Noto fonts are published under the SIL Open Font License, Version 1.1. Noto is a trademark of Google Inc. (https://www.google.com/get/noto/).

ISSN: 2647-4832 (online only)

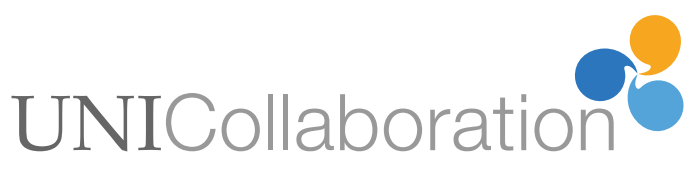

